\title{
Cenplestao
}

\section{Homero Pires: o colecionismo bibliográfico e as marcas de proveniência}

\author{
Raphael Diego Greenhalgh \\ Doutor; Universidade de Brasília (UnB), Brasília, DF, Brasil; \\ raphaelrdg@unb.br; ORCID: https://orcid.org/0000-0002-9625-5854
}

\begin{abstract}
Resumo: O presente trabalho consiste no levantamento, descrição e análise documental das marcas de proveniência deixadas pelo político e bibliófilo Homero Pires em seus livros dos séculos XVI e XVII. Das 165 obras deste período presentes na Seção de Obras Raras da Biblioteca Central (BCE) da Universidade de Brasília (UnB), 92 pertenceram ao referido colecionador. Além das anotações e marcas de posse deixadas pelo bibliófilo, também foram observadas as marcas de proveniência dos que anteriormente tiveram contato com os exemplares. Portanto, verificou-se, entre outras coisas, que essas marcas apresentam informações relevantes sobre a circulação de livros, sobre as práticas do colecionismo bibliográfico e sobre a venda de livros raros no Brasil na primeira metade do século XX.
\end{abstract}

Palavras-chave: Homero Pires; Bibliofilia; Livros raros; Marcas de proveniência; Bibliografia Material

\section{Introdução}

Homero Pires foi um político e bibliófilo, cuja coleção particular foi adquirida pela Biblioteca Central (BCE) da Universidade de Brasília (UnB). Em um projeto que levantou elementos da materialidade das obras dos séculos XVI e XVII presentes na Seção de Obras Raras da BCE, foi possível verificar que boa parte das obras deste período de publicação haviam pertencido a este colecionador, que frequentemente colocava marcas de posse em seus exemplares e fazia anotações manuscritas nas obras. Além disso, os itens apresentam marcas de posse e proveniência de outras pessoas ou instituições que também tiveram contato com eles. Portanto, a partir desse levantamento surgiu a necessidade de analisar as marcas de proveniência presentes nestes exemplares, de modo a verificar o que elas poderiam revelar sobre a circulação dos livros e as práticas do colecionismo bibliográfico. 
As perguntas que nortearam o presente trabalho foram: qual a relevância das obras da coleção de Homero Pires para o acervo de Obras Raras da BCE? Quais as marcas de posse adotadas por este bibliófilo? O que as marcas de proveniência deixadas por ele mostram sobre as práticas de colecionismo bibliográfico na primeira metade do século XX? E o que as marcas de proveniência nas obras dele mostram sobre a venda de livros raros no Brasil? Para tanto, foi realizada uma análise documental quali-quantitativa dos dados, levantados a partir de uma pesquisa descritiva e exploratória sobre as marcas de proveniência presentes nas obras dos séculos XVI e XVII que pertenceram a Homero Pires e que hoje estão na Seção de Obras Raras da BCE.

Em um primeiro momento, buscou-se identificar entre os 165 livros impressos nos séculos XVI e XVII presentes nas Obras Raras da Biblioteca Central da UnB quais exemplares pertenciam a Homero Pires, identificados a partir das marcas de posse deste bibliófilo e de suas anotações manuscritas nas obras. Depois, foram levantadas todas as marcas de posse e proveniência presentes nas obras dele, sejam as que ele usava ou de outras pessoas ou instituições que tiveram contato com aquele exemplar, identificando a tipologia destas marcas e a frequência com que apareciam. Após estas etapas, buscou-se levantar e analisar as marcas de proveniência deixadas pelo próprio Homero Pires, encontrando dados quantitativos e qualitativos referentes aos termos e assuntos recorrentes, de modo a sistematizar alguns elementos como, por exemplo, a indicação de local e data que ele colocava abaixo de sua assinatura. Ou, ainda, as fontes bibliográficas que ele usou para identificação da relevância dos autores ou títulos em sua coleção.

Por fim, foram analisadas as anotações manuscritas nos exemplares, sejam do próprio Homero Pires, as mais frequentes, ou de outros sujeitos. Também foram identificados alguns valores de venda dos exemplares, anotados nos itens, e considerações de Homero Pires sobre elementos específicos dos seus exemplares, como a presença de uma gravura rara ou condição de conservação, buscando identificar os elementos de personificação do bibliófilo enquanto indivíduo e os elementos simbólicos presentes na sua relação com a sua coleção, 
mas também as práticas comuns ao colecionismo bibliográfico do período em que ele estava inserido.

Neste sentido, verificou-se que Homero Pires fazia uso de três marcas de posse (ex libris ${ }^{1}$, super-libros ${ }^{2}$ e assinatura) e, a partir das suas anotações, foi possível identificar as bibliografias usadas por ele para levantamento de informações sobre conteúdo, autor, impressor e detalhes da edição e dos seus itens. De modo que, neste contexto, foram observados elementos inerentes às práticas do colecionismo bibliográfico, como verificação e atribuição de raridade, comparação entre exemplares, pesquisas sobre a presença de determinado título em outras coleções particulares e públicas de referência, identificação de proveniência, entre outros. Dessa forma, o presente estudo permitiu, ainda, a análise de aspectos da atuação de algumas livrarias brasileiras, principalmente da Livraria J. Leite, do Rio de Janeiro, de onde vieram parte das obras analisadas.

\section{Homero Pires e seus livros na BCE}

Homero Pires foi um jurista, professor, escritor e político brasileiro, que nasceu na cidade baiana de Ituaçu no dia 7 de fevereiro de 1887. Formou-se em Direito em 1910 e teve ampla participação na política nacional. Seu primeiro mandato como deputado federal por seu estado de origem foi entre maio de 1924 e dezembro de 1926. Ele se reelegeu para o cargo nas duas legislaturas seguintes, tendo o mandato interrompido em outubro de 1930, em razão da vitória do movimento que depôs o presidente Washington Luís e conduziu Getúlio Vargas ao poder.

Conforme informações retiradas da página do Centro de Pesquisa e Documentação de História Contemporânea do Brasil da Fundação Getúlio Vargas, ele também foi eleito à Assembleia Nacional Constituinte em maio de 1933, participando da Comissão de Redação da Carta Magna de 1934, tendo o mandato prorrogado até maio de 1935. Exerceu também legislatura ordinária entre outubro de 1934 e novembro de 1937. Também foi do conselho consultivo da Companhia Hidroelétrica do São Francisco de março de 1948 a abril de 1950, diretor da Casa de Rui Barbosa, professor catedrático de direito público e 
constitucional na Faculdade de Direito da Bahia e de teoria geral do Estado na Faculdade de Direito da Universidade do Estado da Guanabara, atual Universidade do Estado do Rio de Janeiro (UERJ), além de membro da Academia Baiana de Letras. Faleceu no Rio de Janeiro no dia 4 de julho de 1962 (FUNDAÇÃO GETÚLIO VARGAS, 2009).

Após o seu falecimento, a BCE adquiriu sua biblioteca particular, em maio de 1963. Segundo Lacerda (2017, p. 2681), neste acervo vieram "30 mil volumes, incluindo obras de Rui Barbosa, Castro Alves, Camilo Castelo Branco e Camões", além de outros itens. Junto à biblioteca deste bibliófilo, também foi para a BCE uma coleção de ex libris que pertenceu a Homero Pires, conforme afirma Bertinazzo (2012). Também hoje estão abrigadas na Seção de Obras Raras da BCE as correspondências que outros colecionadores de ex libris enviaram a Homero Pires, na tentativa de trocas de exemplares e informações sobre outros colecionadores brasileiros, além do seu diploma de sócio contribuinte no Clube Internacional de Ex libris. Também foram para a BCE outros documentos de destaque como, por exemplo, os manuscritos das obras Água-mãe, de José Lins do Rego, e As Razões do Coração, de Afrânio Peixoto, ambos com dedicatórias dos imortais a Homero Pires.

A coleção de Homero Pires se juntou a outros acervos particulares adquiridos pela Biblioteca Central da UnB entre as décadas de 1960 e 1980. Dentre outras bibliotecas, foram compradas as do jornalista e político Carlos Lacerda, do médico e memorialista Pedro Nava e do crítico literário Agrippino Grieco. As obras raras presentes nestas coleções particulares foram levadas à Seção de Obras Raras, que possui obras impressas desde o século XVI, três manuscritos medievais do século XIV, cartas e documentos dos séculos XIX e XX, coleção de ex libris, arquivo pessoal do Carlos Lacerda, entre outros itens.

Homero Pires deixou registros manuscritos em várias obras do seu acervo que podem trazer alguma informação sobre o colecionismo particular de um bibliófilo, mas também sobre o colecionismo de livros na primeira metade do século XX, assim como podem fornecer elementos sobre a atuação das livrarias brasileiras e consequentemente para a construção da História do Livro deste período. Não só através das marcas de proveniência que ele mesmo legou 
aos seus exemplares, mas também pelas evidências de posse, leitura e circulação deixadas por outras pessoas que também tiveram contato com os itens.

\section{Marcas de proveniência e o colecionismo bibliográfico}

Na história do livro, é possível verificar que várias características extrínsecas à produção de uma obra são adquiridas por alguns de seus exemplares ao longo de sua existência. Características essas que podem dar informações sobre a trajetória histórica de um item e sobre seus proprietários, traçando sua proveniência. Para Rodrigues, Vian e Teixeira (2020, p. 3) as marcas de propriedade, as anotações manuscritas e as dedicatórias ou autógrafos presentes em um livro definem a "chamada procedência, ou, proveniência, de uma obra rara". Também estão associadas a este contexto, as marcações feitas por impressores, papeleiros, livreiros e encadernadores, pois também fornecem informações importantes sobre a produção e circulação de determinados livros.

Dentro das características apresentadas, é possível verificar que a indicação de proveniência de um livro está presente não só nas marcas de propriedade (carimbos, ex libris, assinaturas, super-libros, etc.), mas também nas marcas de circulação ${ }^{3}$, como etiquetas de livrarias e encadernadores. É importante evidenciar essas duas dimensões, pois as marcas de propriedade têm a intenção de "identifica[r] um documento como pertencente a um determinado particular ou instituição" (FARIA; PERICÃO, 2008, p. 483), enquanto as marcas de circulação, por vezes, têm a função de publicidade.

As primeiras etiquetas de encadernador surgiram na França e na Inglaterra por volta de 1720 e a prática se tornou comum na virada para o século XIX, funcionando como uma publicidade dos serviços, segundo Lock $\left(2003^{4}\right.$ apud TARTAGLIA, 2018). As etiquetas de livrarias eram uma forma dos livreiros "de estampar na obra que comercializavam a identificação de suas atividades" (MACHADO, 2003, p. 17). Neste sentido, Lopes, Gonçalves e Rodrigues (2021) indicam que as pesquisas sobre proveniência: 
censores, bibliotecas e comerciantes. (LOPES; GONÇALVES; RODRIGUES, 2021, p. 1).

Levando em consideração os elementos de posse e uso do livro como constituintes da proveniência das obras, Leung (2016) define proveniência:

[...] como uma cronologia de proprietários, custódia ou localização de um livro histórico. Inclui não apenas nomes, mas outras informações contextuais de interesse para a história do livro (como tempo e lugar) para permitir um melhor entendimento das interações das pessoas com os livros ao longo do tempo. (LEUNG, 2016, p. 11, tradução nossa) $)^{5}$.

No entanto, Josserand (2016) diz que a proveniência é:

[...] qualquer vestígio em um livro ou fora dele, fornecendo evidências contextuais e circunstanciais de sua produção original ou sua descoberta, [que] permita traçar, tanto quanto possível, sua história, em particular as sequências de sua apropriação formal. (JOSSERAND, 2016, p. 12, tradução nossa) ${ }^{6}$.

Unindo os dois conceitos anteriores, Lopes, Gonçalves e Rodrigues (2021) apontam:

De maneira simplificada, podemos definir proveniência, no âmbito da Biblioteconomia, como qualquer vestígio encontrado em uma obra (dentro ou fora dela), que forneça evidências contextuais e circunstanciais de sua produção e permita traçar, tanto quanto possível, sua história, em particular as sequências de sua apropriação formal (posse e uso). (LOPES; GONÇALVES; RODRIGUES, 2021, p. 1-2).

Portanto, entendendo que os "livros podem ser reunidos e usados longe de seus locais de origem ${ }^{7 \prime \prime}$, conforme afirma Mckitterick (2018, p.42), os registros das coleções de bibliotecas que trazem informações sobre a proveniência, anotações e encadernações de suas coleções podem auxiliar nos estudos e levantamentos sobre o mercado livreiro, visto que, "a geografia da produção [dos livros] era muito diferente da geografia do uso ${ }^{8,}$ (MCKITTERICK, 2018, p. 43, tradução nossa).

Para além da história da comercialização e circulação dos livros, ao falar das marcas de propriedade dos livros antigos da Nova Espanha, Carreño Velázquez (2015) diz que elas também são partes da história da leitura, dos leitores, das bibliotecas e da arte de imprimir. 
Nesse sentido, o leitor, o bibliotecário e os amantes dos livros criam emblemas com letras, imagens ou signos que os identificam e através dos quais se definem e se valorizam ${ }^{9}$ (CARREÑO VELÁZQUEZ, 2015, p. 41, tradução nossa).

Em relação aos estudos de proveniência pelas bibliotecas, Galbraith e Smith (2012) apontam algumas possíveis dificuldades, como o estabelecimento da veracidade da assinatura de alguém importante ou mesmo a identificação se um ex libris foi colocado em uma obra por seu proprietário ou adicionado por outra pessoa posteriormente, apenas para valorizar o exemplar. Contudo, os autores também destacam a importância do levantamento destas marcas nos livros, pois mesmo que as bibliotecas de livros raros muitas vezes não tenham recursos para estudar e traçar todas as etapas para confirmação exata da proveniência de uma obra, a indicação das marcas encontradas em seus livros, em catálogo público, pode ser o motivo de um pesquisador consultar determinado exemplar, por ele possuir alguma assinatura ou ex libris, por exemplo.

Sobre a evolução dos estudos a respeito da proveniência, o Consortium of European Research Libraries (CERL) diz que:

[o] interesse em informações de proveniência entra e sai de moda. Antigamente, era um interesse bibliofílico preocupado com associação de cópias de autores e livros pertencentes a grandes homens. Seguindo a ascensão da história do livro nas décadas de 1980 e 1990, os estudos de proveniência se tornaram um ingrediente importante no trabalho de historiadores sociais e culturais que lidam com questões dos leitores e da alfabetização. A propriedade de livros de artesãos e mulheres é agora tão significativa quanto a de reis e arcebispos. Ao mesmo tempo, um desenvolvimento separado sobre a preocupação com a segurança das coleções de bibliotecas aumentou o interesse em registrar procedências de todos os tipos, antigas e modernas (CONSORTIUM OF EUROPEAN RESEARCH LIBRARIES, 2020, s.p., tradução nossa $)^{10}$.

Neste sentido, o levantamento das marcas de proveniência, além de fornecer informações aos pesquisadores sobre a origem e circulação das obras, também contribui para a segurança das coleções, conforme mostra o texto do CERL. Sobre essa dimensão do uso das marcas de proveniência, Greenhalgh e Manini (2015) ressaltam que a análise bibliológica de um exemplar, com o levantamento exaustivo de caraterísticas intrínsecas e extrínsecas à produção da 
obra, permite a individualização de exemplares e com isso a indicação indubitável da propriedade deste item pela instituição mantenedora. Além disso, o estudo das marcas de proveniência também permite que as bibliotecas participem da escrita de sua própria história, a partir da construção da trajetória de suas coleções, como ressalta Josserand (2016). Desse modo, fica evidente a importância do levantamento das marcas de proveniência presentes nos acervos das bibliotecas, tanto para os pesquisadores de história do livro, da leitura e do colecionismo, quanto para as próprias bibliotecas.

Os estudos de marcas de proveniência, portanto, estão associados ao entendimento do livro enquanto objeto, mantenedor de um conteúdo em sua materialidade, para além da informação textual que está presente nos diversos exemplares de uma edição, de um determinado título. Aproximam-se, desta forma, dos estudos relacionados ao colecionismo bibliográfico, buscando compreender as relações que o bibliófilo estabelece com o objeto livro, assim como as possibilidades de ressignificações deste objeto a partir desta interação.

O trabalho de Sundström e Albuquerque (2020) traz uma perspectiva geral dos estudos brasileiros sobre colecionismo bibliográfico no contexto da Ciência da Informação (CI). As autoras identificaram três correntes destes estudos no país: a primeira está ligada a uma visão patológica do ato de colecionar, buscando compreender as razões do colecionismo do ponto de vista do colecionador. A segunda vertente, chamada pelas autoras de documental, corresponde às análises da importância dos colecionadores e suas coleções para a cultura nacional, entendo que, ao serem institucionalizadas, as coleções passam a ser consideradas como importantes representantes de elementos de uma cultural geral. Já a terceira corrente, a financeira, está associada "ao valor de troca simbólica, no qual os elementos de coleção estão associados ao valor cultural de que eles são investidos e também à impossibilidade do acesso" (SUNDSTRÖM; ALBUQUERQUE, 2020, p. 269).

Verifica-se também que o conceito de semióforo tratado por Pomian (1984) é frequentemente usado nos estudos brasileiros sobre colecionismo bibliográfico, na tentativa de entender a força simbólica dada pelos colecionadores às coleções, de modo a identificar elementos desta relação para a 
gestão de acervos no contexto da Biblioteconomia e da gestão de coleções institucionalizadas. Portanto, tendo o entendimento de que um semióforo é aquele objeto que é um símbolo, que carrega um significado não visível, transcendente da sua forma material e da sua utilidade primária, passível de reconhecimento somente a partir da compreensão da sua relação com algo ou alguém que lhe atribuiu valor representacional (CARVALHO; ALMEIDA, 2019).

Ao buscar analisar os livros como semióforos, Murguia (2009) propõe a análise das coleções em bibliotecas a partir da materialidade do suporte destes itens, entendendo estes objetos para além da sua informação textual e utilidade primária, buscando reconstruir a memória e identidade de grupos ou indivíduos e estabelecendo as relações que os sujeitos mantêm com os livros, inclusive o colecionismo. Esta abordagem, segundo Sundström e Bizello (2016), poderia ampliar o tratamento documental dentro da Biblioteconomia, assim como auxiliar e ampliar as ações de controle de acervos dentro do espectro do desenvolvimento de coleções, contemplando não só a análise dos elementos textuais, mas também o sentido simbólico dos livros.

\section{As marcas de posse e proveniência de Homero Pires: apresentação e análise dos dados}

Dos 165 volumes dos séculos XVI e XVII presentes nas Obras Raras da Biblioteca Central da UnB, 92 pertenciam a Homero Pires. Ou seja, cerca de $56 \%$ vieram deste colecionador, sendo a maioria das obras impressas mais antigas do acervo da BCE provenientes da coleção deste bibliófilo. Este dado funciona como um indício da relevância das obras vindas nesta compra e do impacto delas para o acervo da biblioteca, devido a raridade destes itens, que não são encontrados em qualquer coleção; representando um período de produção artesanal do livro e do colecionismo destes objetos.

$\mathrm{Na}$ análise das obras que pertenceram a Homero Pires, é possível verificar que ele tinha o costume frequente de indicar sua posse nos exemplares. Nas 92 obras provenientes de sua coleção, em 69 (75\%) há ao menos um ex libris, um super-libros ou uma assinatura dele. Outros 21 exemplares, sabe-se 
terem pertencido a Homero Pires devido às marcações feitas pela Biblioteca Central no tratamento da coleção, enquanto os outros dois atribui-se a ele devido às anotações nas obras, com letra e características similares às das demais.

A forma principal adotada por Homero Pires para distinguir seus exemplares como sua propriedade foi a assinatura (Imagem 1). Sua firma manuscrita indicava seu nome e sobrenome de forma legível, geralmente acompanhada de local e data. O seu uso como principal marcação de posse pelo bibliófilo provavelmente se deu pela facilidade da sua adição à obra, aparecendo em $66(95,65 \%)$ dos exemplares que apresentam marcas de propriedade.

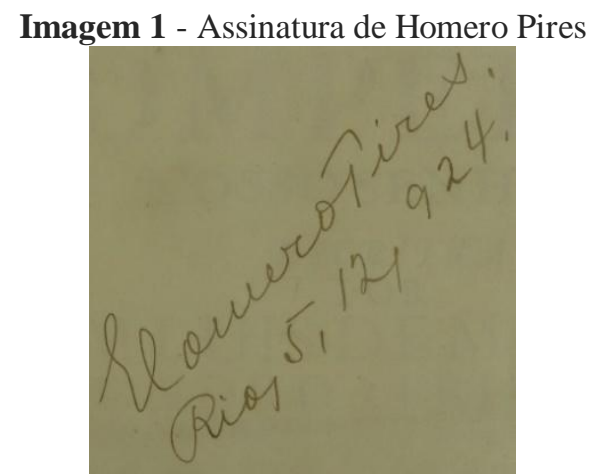

Fonte: Imagem do autor a partir de exemplar da coleção de Homero Pires

Das 66 obras com assinatura, 63 também apresentam informações sobre local e data. Verificou-se que, na indicação de localidade, estão assinalados apenas os estados da Bahia e do Rio de Janeiro, sendo que, naquelas datadas pelo colecionador entre 15 de agosto de 1912 e 21 de março de 1924, todas trazem como local a Bahia, o que acontece em 29 exemplares. Para aquelas datadas a partir de 18 de abril de 1924 e até 14 de setembro de 1954, com exceção de uma obra de 19 de maio de 1925, em que consta a Bahia como local assinalado, todos os demais 35 exemplares apresentam indicação do Rio de Janeiro. Essas informações provavelmente se relacionam com o momento de aquisição dos itens, possivelmente indicando que todos ou a maioria deles foram adquiridos no mercado brasileiro ou por intermédio de comerciantes brasileiros, com Homero Pires os recebendo em território nacional. 
A preferência pela assinatura como marca de posse chama atenção pelo fato de Homero Pires ter possuído um ex libris próprio (Imagem 2), além de ter colecionado ex libris e participado de associações e exposições desta arte.

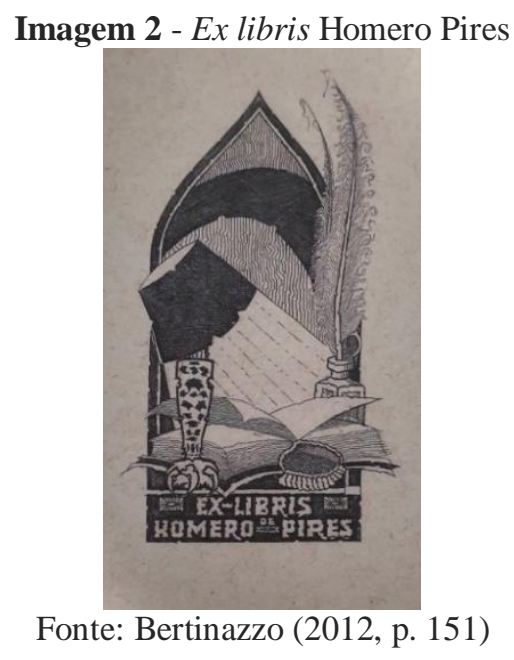

Nas obras analisadas, dos séculos XVI e XVII, o bibliófilo inclusive preteriu o uso do ex libris em relação ao super-libros (Imagem 3). Em apenas sete exemplares ele afixou seu ex libris, enquanto fez uso do super-libros em 13 exemplares. Todos os super-libros identificados correspondem às iniciais H.P., gravadas em douração no pé da lombada das obras.

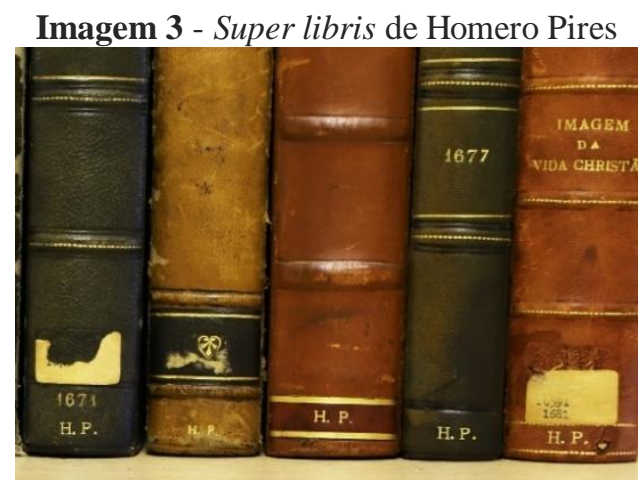

Fonte: Imagem do autor

Apesar de Homero Pires ter adquirido obras contendo carimbos de livrarias e proprietários anteriores, nas obras analisadas ele mesmo não fez uso dessa técnica para marcação de sua posse. Destaca-se também o uso que o bibliófilo fazia de mais de uma tipologia de marca de propriedade em um 
mesmo volume, usando por vezes as suas três formas de marcação, conforme mostra o Quadro 1.

Quadro 1 - Marcas de posse em um mesmo exemplar

\begin{tabular}{|l|c|}
\hline \multicolumn{1}{|c|}{ Marcas de posse } & $\begin{array}{c}\text { Quantidade de } \\
\text { exemplares }\end{array}$ \\
\hline Somente ex libris & 02 \\
\hline Somente super Libris & 01 \\
\hline Somente Assinatura & 53 \\
\hline Ex libris e Assinatura & 01 \\
\hline Super libris e Assinatura & 08 \\
\hline Ex libris, super libris e Assinatura & 04 \\
\hline
\end{tabular}

Fonte: Elaborado pelo autor.

O uso frequente das marcas de posse na maioria das obras analisadas, assim como o uso de tipologias diferentes destas marcas em um mesmo exemplar, pode representar não só a necessidade de uma indicação de posse por motivos de segurança, mas também o desejo de perpetuação de si, que o colecionador projeta em sua coleção, como aponta Ribeiro (1998, p. 35), que diz ser o colecionismo "[...] o meio mais direto de preservar-se".

Além das marcas de posse, verifica-se que o bibliófilo tinha o costume de fazer anotações em suas obras (Imagem 4), geralmente nas guardas iniciais do exemplar e - de forma menos frequente - também nas guardas finais. Homero Pires escrevia à mão passagens das bibliografias especializadas que consultava, trazendo informações sobre a importância do título, autor, impressor, entre outros aspectos do volume. 


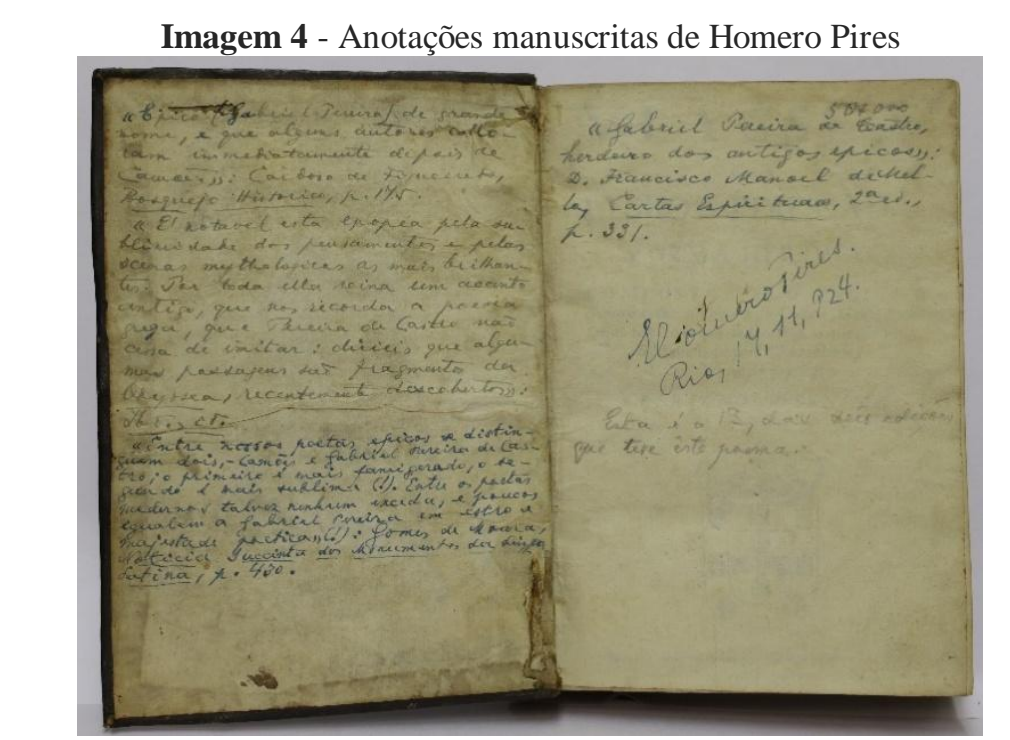

Fonte: Imagem do autor a partir de exemplar da coleção de Homero Pires

Nas anotações manuscritas presentes na obra Ulissea ou Lisboa edificada: poema heroico, de 1636 (reproduzidas na Imagem 4), verifica-se que o levantamento bibliográfico feito por Homero Pires gira em torno da importância do autor da obra, como pode ser visto no trecho abaixo:

"Entre nossos poetas épicos se distin-// guem dois, - Camões e Gabriel Pereira de Cas-// tro; o primeiro é mais famigerado, o se-// gundo é mais sublime (!). Entre os poetas// modernos talvez nenhum exceda, e poucos// igualem a Gabriel Pereira em astro e// majestade poética" (!): Gomes de Moura,// Noticia succinta dos momentos da língua// latina, p. $430 .^{11}$

Enquanto na obra História geral de Ethiopia, do Padre Manoel D’Almeida, revisada pelo Padre Baltazar Teles, impressa em 1660, além do levantamento de informações sobre o revisor, Homero Pires também pesquisou sobre a raridade da obra, escrevendo:

São muito escassos os exemplares existentes desta obra,// que José Feliciano de Castilho, há annos, collocou na// conhecida e seguida Relação das espécies raras e pre-// ciosas da Bibliotheca Nacional de Lisboa.

Entre as orientações que Moraes (2005) dá para quem queira iniciar na bibliofilia está a premissa de que não se constrói uma coleção sem a consulta de bibliografias. Neste sentido, nas anotações de Homero Pires é possível ver 
materializada essa condição inerente ao colecionismo de livros. Anotações que inclusive podem servir de referência aos pesquisadores e bibliotecários que lidarem com aquela obra, mas que também trazem as preferências do próprio Homero Pires nas bibliografias consultadas, visto que:

[...] cada bibliófilo necessita de um tipo de bibliografia, conforme o assunto ou o autor que coleciona. [...] O próprio bibliófilo é que deve escolher a sua ferramenta, de acordo com o trabalho que pretende realizar (MORAES, 2005, p. 110).

No caso anteriormente apresentado, Homero Pires também faz uso da bibliografia especializada para indicação da raridade da obra, relacionando com a reputação do Padre Baltazar Teles, para justificá-la, como pode ser visto no trecho a seguir:

No abundante e rico Catalogo de Solidonio Leite fi-// gura sob o $\mathrm{n}$. 270 , à pag. 72, com esta nota: "Muito// estimada e raríssima". Assim se justifica ser// Balthasar Telles, clássico dos mais bem reputados,// muito pouco citado.

Verifica-se, portanto, que a raridade bibliográfica era uma condição buscada e estudada por Homero Pires nos itens que adquiria, e que certamente influenciava na decisão de compra de determinados exemplares, pois ele fez indicações sobre a raridade das obras em 16 dos seus exemplares. É possível dizer que a raridade se configura como um dos eixos simbólicos que norteia a construção da coleção bibliográfica deste colecionador, mostrando como se tornam semióforos parte dos livros de Homero Pires, visto que essa categoria de valor transcende a função original dos objetos, se aproximando do caráter expositivo deles, como ressaltam Pomian (1984) e Murguia (2009).

Como visto na passagem acima, ele fazia uso das bibliografias especializadas para verificação da raridade dos itens e, por vezes, ainda reforçava este entendimento, a partir da ausência de um título em outras coleções de referência. Por exemplo, em uma edição dos Lusíadas, de 1670, o bibliófilo escreve: "Edição rara. Não// a possuíam as bibliothecas Adamson,// Samodães e outras// importantes." Informação complementada por pesquisa realizada por Homero Pires no Manual bibliographico portuguez de livros raros, classicos e curiosos, de Ricardo Pinto de Mattos, conforme anotação dele 
no exemplar: "Ricardo de Mathos, Ma-// nual,_p. 97: 'Tanto a edição// das Rimas, como a dos// 'Lusíadas desta data (1670),// que forma coleção, não'// são vulgares". Esta verificação da presença da obra em outras bibliotecas também é observada nas anotações de Homero Pires em exemplar de Meditações dos atributos divinos, de 1671:

A $1^{\text {a }}$ edição deste livro, de// que este volume é um exem-// plar, é raríssima, e não a// teem as ricas colecções da// Bibliotheca Nacional do Rio,// do Gabinete Português de Lei-// tura do Rio e a biblioteca// do Mosteiro de S. Bento.// Também não está incluída no// copioso Catalogo da biblio-// theca Azevedo Samodães.// Ainda são mais raros os exem-// plares que, como este, tra-// zem o retrato do P. Diogo// Monteiro.

Esta anotação mostra também que Homero Pires estava atento às características específicas das publicações que não eram encontradas em todos os exemplares, atribuindo mais raridade aos que tem "o retrato do P. Diogo Monteiro", autor da obra. Condição que também é observada nas anotações manuscritas do bibliófilo em Conversão meraculosa da felice AEgypcia penitente, de 1674, onde consta: "Traz a gravura, que// raramente apparece".

Araújo, Reis e Silveira (2018, p. 53), ao analisarem as bibliografias de livreiros produzidas no século XVIII, concluem que "a raridade é projetada, construída e disseminada no território da Bibliofilia pela comunidade de atores que constituem e que conferem dinamicidade ao universo librario". Neste sentido, sendo a raridade uma construção social, possivelmente variável em diferentes períodos e localidades, o fato de Homero Pires ter deixado anotado em suas obras quais a fontes que consultou para identificação dos diversos elementos presentes na obra, no intuito de verificação e atribuição de importância aos exemplares, também permite observar quais títulos e autores lhe influenciavam diretamente no entendimento da raridade de seus itens.

Homero Pires, portanto, para atribuição de raridade de seus exemplares, fazia uso principalmente de catálogos de bibliotecas particulares e de leilões, manuais especializados em livros raros e biobibliografias, obras publicadas durante o século XIX e no início do século XX. Certamente este uso se fez na busca de uma noção de raridade mais próxima da realidade de seu tempo, 
fazendo pouco uso das bibliografias especializadas de livreiros e bibliógrafos do século XVIII e de períodos anteriores. Era frequentemente citado pelo bibliófilo o Dicionário bibliográfico portuguez, do Innocencio Francisco da Silva, publicado entre 1858 e 1870, continuado pelo jornalista Brito Aranha, que publicou outros volumes até 1911. Também são citados os catálogos das bibliotecas dos Condes de Azevedo e de Samodães, de 1921, e da biblioteca de Solidônio Leite, publicado em 1930.

Na obra Lusiadum: libri decem, publicado em 1622, é possível ver o uso que Homero Pires fazia das bibliografias especializadas na atribuição de raridade, onde ele escreve à mão: "Brunet, I, p. 1518: 'Cette tradu-// tion latine est fort rares'.// Catalogo Azevedo-Samodães, I,// p. 161.: 'Rarissima'// Ricardo de Mattos, Manual,// p. 118: 'É livro estimado e raro"'. Mostrando, portanto, que realizava suas pesquisas nas obras Manuel du libraire et de l'amateur des livres, de Jaques Charles Brunet, Catálogo da importante e preciosíssima livraria que pertenceu aos notáveis escritores e bibliófilos Condes de Azevedo e de Samodães e o já citado Manual bibliographico portuguez de livros raros, classicos e curiosos, de Ricardo Pinto de Mattos.

Outras informações que chamam atenção nas anotações manuscritas de Homero Pires são aquelas referentes às comparações de exemplares. Elas demonstram o constante trabalho de pesquisa do colecionador para o entendimento do exemplar que tem em mãos, buscando situá-lo dentro do contexto de sua própria edição e diante das demais edições do mesmo título. Para a obra Palavra de Deos empenhada e desempenhada, do Pe. Antônio Vieira, de 1690, Homero Pires comparou em minúcias seu exemplar com um outro que ele disse pertencer à Editora Anchieta, como visto nas folhas manuscritas soltas encontradas dentro do exemplar da BCE.

Entre os vários elementos da obra que são analisados pelo bibliófilo, vêse a identificação de inconsistências entre os dois exemplares, no tipo usado em diferentes partes da obra, como por exemplo, na folha de rosto, em que Homero Pires aponta: "ambos os exempla,// res guardam a mesma disposição de// linhas, que começam e acabam sempre// nas mesmas palavras. Mas os tipos// empregados são diferentes, embora da// mesma família ou desenho". Ele 
também encontrou diferenças entre os exemplares na grafia de várias palavras, na quantidade de páginas numeradas, na ornamentação das obras, nas páginas onde alguns sermões terminavam e até mesmo na qualidade da revisão ortográfica dos exemplares, apontando que um exemplar apresenta mais erros que o outro.

A meticulosidade de Homero Pires na comparação dos exemplares neste caso, justificava-se no fato de existirem múltiplas contrafações das obras do Viera. Sobre o livro Palavra de Deos empenhada e desempenhada, Lima (no prelo) informa que ele teve duas impressões feitas na oficina de Miguel Deslandes e que também foram identificadas duas contrafações editadas provavelmente no século XVIII, por Antônio Pedro Galrão. O autor ainda revela que o exemplar presente na BCE, ou seja, o que pertenceu a Homero Pires, é uma dessas versões piratas, que divergem da original na disposição do texto, na paginação e no número de páginas, como havia identificado o bibliófilo.

Todas estas pesquisas e estudos dos exemplares evidenciam um comportamento de Homero Pires em busca de entender o contexto de produção a que estão inseridos os seus livros, que trazem para si a compreensão sobre circulação e produção destes itens, pois "colecionar significava também ter conhecimento" (PEDRÃO; MURGUIA, 2013, p. 400). Neste caso, tal conhecimento foi projetado ao futuro pelo próprio bibliófilo, a partir de suas anotações nos exemplares, também no sentido de se perpetuar por meio de sua coleção, como já mencionado.

Ainda como parte dos seus esforços em conhecer bem o exemplar que tinha adquirido, mas também em manter controle pessoal sobre a aquisição do item, Homero Pires também indicava, com frequência, informações sobre as datas das diversas edições daquele título, erros de paginação, completude do exemplar e também valor de compra. Em 11 exemplares há a indicação de quanto o item custou, por vezes acompanhada da expressão "sem a encadernação", que provavelmente se tornou um custo adicional posterior ao colecionador. Essas anotações são testemunhos materiais de que o "colecionador de livros é dono de um acervo que evidencia um investimento de tempo, 
dinheiro, conhecimento, energia e que reforça suas características pessoais" (PEDRÃO; MURGUIA, 2013, p. 404).

\section{Outros percursos dos livros}

Além das marcas de proveniência que Homero Pires deixou em alguns dos seus exemplares, também foram encontradas outras características materiais que dão indícios sobre a trajetória dos itens. Marcações que provavelmente foram adicionadas às obras em períodos anteriores à sua incorporação na coleção de Homero Pires.

A análise destas marcas de proveniência revelou algumas curiosidades relacionadas à trajetória dos livros ao longo de sua existência, pois estes caminhos não seguem necessariamente uma configuração linear, onde um exemplar vai passando de pessoa a pessoa, até se depositar em uma instituição. Um exemplo disso pode ser visto nas anotações manuscritas na segunda capa da obra Chronica de el Rey Dom Afonso, de 1653, que pertenceu a Homero Pires, onde são vistas duas anotações manuscritas de pessoas distintas. A primeira iniciada com a inscrição: "T. Norton// Porto $268^{\text {bro }}$ 1846.// J'. Monteverde.// Encadernação 3 vo.", que vem acompanhada de comentários gerais sobre a contenda entre os reis D. Afonso XI, de Castela, e D. Afonso IV, de Portugal. Contudo, a segunda, de autoria de J. Monteverde, aponta que ele ofereceu a obra a Thomaz Norton e depois a arrematou de volta no leilão da biblioteca daquele que havia presenteado ${ }^{12}$.

Monteverde ainda adicionou mais informações sobre esse percurso da obra, dizendo que quando a deu, ela estava brochada em pergaminho, e que Norton em seu "mau gosto" substituiu a encadernação anterior por uma 1/2 encadernação. Informação que permite situar em que período a encadernação atual foi adicionada ao exemplar e como ele se apresentava antes disso. A partir de registros como esse, se torna possível traçar, mesmo que por vezes de forma fragmentária e incompleta, a sequência da apropriação formal dos livros, como apontado por Josserand (2016). 
Dentre as marcas de posse de outras pessoas que não Homero Pires, os carimbos e as inscrições manuscritas foram as mais encontradas, presentes em 22 exemplares cada, conforme pode ser visto no Quadro 2.

Quadro 2 - Marcas de posse de outras pessoas ou instituições
\begin{tabular}{|l|c|}
\hline \multicolumn{1}{|c|}{ Marcas de proveniência } & $\begin{array}{c}\text { Quantidade de } \\
\text { exemplares }\end{array}$ \\
\hline Ex libris & 04 \\
\hline Carimbos & 22 \\
\hline Etiquetas de livraria & 03 \\
\hline $\begin{array}{l}\text { Assinaturas ou inscrições } \\
\text { manuscritas }\end{array}$ \\
\hline \multicolumn{2}{|c|}{ Fonte: Elaborado pelo autor } \\
\hline
\end{tabular}

Em relação aos ex libris, destacam-se os de Simões Corrêa e Solidônio Leite, que permitem inferir que as obras Rimas várias de Luis de Camões, com os tomos I e II, de 1685, encadernados juntos com o tomo III, de 1689, e Ecco político, de 1645, tenham pertencido a estes senhores. Sobre Álvaro Simões Correa, por exemplo, a partir do trabalho de Pinheiro e Vicente (2019), é possível dizer que ele foi um médico, nascido no final do século XIX e falecido em 1961, filho do também médico Francisco Simões Correa, formado pela Faculdade de Medicina do Rio de Janeiro em 1907 e membro da Associação Brasileira de Imprensa. Já Solidônio Leite (1867-1930) foi um filólogo que ocupou cargos públicos importantes, como deputado federal e consultor-geral da República, como mostra Machado (2012), tendo o bibliófilo parte da sua coleção divulgada no Catalogo annotado da Bibliotheca de Solidonio Leite: primeira parte. Estes Ex libris se tornam peças essenciais na recuperação da história da circulação e posse dos livros. Sem a presença destas etiquetas nestes itens específicos, não existem outros elementos que liguem os itens aos donos anteriores a Homero Pires.

Em anotação manuscrita de Homero Pires na obra Raizes da língua latina, de Amaro Roboredo, impressa em 1621, encadernada juntamente com a obra Porta de línguas, de mesma autoria e impressa em 1623, é possível ver um registro a respeito de uma prática bibliofílica de Solidônio Leite, que aparentemente guardava seus itens mais preciosos em um cofre. Homero Pires escreveu: "São ambas extremamente// raras. Este exemplar, que// foi de 
Solidonio Leite, êle// o tinha em cofre de ferro", reforçando, com esta anotação, o caráter de raridade da obra, por tão respeitado bibliófilo a guardar de forma tão segura. Faz também uma indicação de proveniência, visto que, sem esta anotação manuscrita, não seria possível conectar Solidonio Leite à obra, pela ausência de outras marcações que indicassem essa posse. Este exemplo e o anterior se configuram em formas diversas de estabelecer a sequência histórica da posse de um objeto.

É possível observar também que muitas das obras de Homero Pires pertenceram a clérigos e instituições religiosas. Entre os nomes que aparecem assinalados à mão nos exemplares estão os dos Fr. Manuel de Sancta Thereza, Pe. M. el Luiz Vaz e Pe. Silvestre Correa da Sylva. Também é possível observar a notação manuscrita e o carimbo da Libreria dello Spirito Santo de Raveña e o carimbo Massiliae Soc. Jes. JHS, que segundo o catálogo da Bibliothéque de L'Institut de France corresponde à marca do Observatoire Sainte-Croix des Jésuites de Marseille ${ }^{13}$, apontado por Homero Pires como "da biblioteca dos padres jesuitas de Marselha".

Nas obras Teatro dos triunfos divinos, de 1658, e Conversão miraculosa da felice aegypciaca penitente, de 1674, estão presentes carimbos da Casa de Azevedo. Ou seja, estes exemplares provavelmente fizeram parte da coleção do conde de Azevedo, Francisco Lopes de Azevedo Velho da Fonseca de Barbosa Pinheiro Pereira e Sá Coelho (1809-1876), e do conde de Samodães, Francisco de Azeredo Teixeira de Aguilar (1828-1918) ${ }^{14}$. Em 1921, a biblioteca dos condes foi dispersada e leiloada, como consta no Catálogo da importante $e$ preciosíssima livraria que pertenceu aos notáveis escritores e bibliófilos Condes de Azevedo e de Samodães. Os títulos dos dois exemplares pertencentes à coleção de Homero Pires estão presentes no referido catálogo como os itens 47 e 933, tendo como nota para o primeiro: "Exemplar falto (sic) do frontispício" (SANTOS, 1921, p.12), enquanto para o segundo foi colocada a observação: "Peq. defeito no frontispício e na primeira follia. RARA." (SANTOS, 1921, p. 262).

As marcas de posse da Casa de Azevedo não passaram despercebidas a Homero Pires, que fez a indicação desta trajetória das obras em suas anotações 
manuscritas nos exemplares. Ele escreveu no Teatro dos triunfos divinos: "Adquiri este exemplar, que// pertenceu a preciosa biblioteca// da casa de Azevedo (Conde// de Azevedo), uma das melhores de Por-// tugal, conforme diz A. Braamcamp// Freire, e em cujo catalogo era o n. 47[...]". No Conversão miraculosa da felice aegypciaca penitente, o bibliófilo escreveu: "pertenceu à bibl. Samo-// dães (n. 933)". Esses elementos mostram que Homero Pires investigava as proveniências das obras que lhe pertenciam e enxergava nelas um fator de valoração e acréscimo de relevância do exemplar.

Pode-se inferir a partir das marcas de proveniência que Homero Pires provavelmente adquiriu boa parte de suas obras nas livrarias do Rio de Janeiro, cidade onde atuou como deputado federal pela Bahia, como professor universitário, como presidente da Casa de Rui Barbosa e onde veio a falecer. $\mathrm{Na}$ já citada História geral de Ethiopia, por exemplo, está a etiqueta da Papelaria da Casa Vallelle. A obra A arte de reynar, de 1644, carrega a etiqueta da Livraria Editora Leite Ribeiro \& Maurillo, que como o nome indica, pertenceu a Leite Ribeiro e Maurillo Quaresma, sendo inaugurada em 1917 e distinta pela “[...] mentalidade empresarial moderna e a utilização de novas técnicas e tecnologias de comunicação, muitas vezes repudiadas por comerciantes mais conservadores" (MACHADO, 2012, p. 156).

Outro suporte a esta interpretação é o fato de que, depois da própria assinatura de Homero Pires em suas obras, o carimbo seco da Livraria J. Leite é a marcação que mais está presente, aparecendo em 18 exemplares. A livraria J. Leite atuou no Rio de Janeiro de 1921 até $1967^{15}$, sendo de propriedade de José Atico Leite, filho do já citado Solidônio Leite, “[...] que dizem ser o verdadeiro proprietário e orientador do negócio", ao menos no início do empreendimento (MACHADO, 2012, p. 180). Ainda segundo Machado (2012), a livraria introduz diversas inovações no mercado carioca, como a criação de um Boletim Bibliográfico, a manutenção de relações com livreiros e editores europeus, de países como Portugal, Espanha, Inglaterra e Alemanha, o oferecimento de serviços de cópias fiéis de documentos presentes nas bibliotecas e arquivos de Portugal e reprodução fac-similar ou manuscrita de folhas que completassem obras raras ou clássicas. Além do fornecimento de livros raros e o atendimento 
ao mercado nacional, como é possível ver a partir das obras da coleção de Homero Pires, a livraria era também especializada no fornecimento de publicações brasileiras ao mercado estrangeiro, conforme mostra Hallewell (2012).

Os boletins bibliográficos da livraria J. Leite serviam como obras de referência para os bibliófilos brasileiros do início do século $\mathrm{XX}$, que os consultavam para entender a raridade bibliográfica e o valor de mercado de algumas obras. Como pode ser visto, por exemplo, nas anotações de Homero Pires na obra Luz, e calor, de 1696, onde está: "No Boletim Bibliographico n. 7 da Livra-// ria J. Leite vem anunciado um exemplar desta edição por $100 \$ 000$, com a nota de raríssima."

Imagem 5 - Marcações de J. Leite

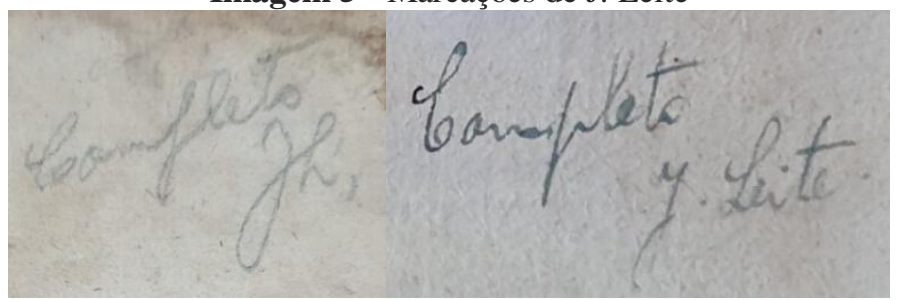

Fonte: Imagens do autor a partir de exemplar da coleção de Homero Pires

Conforme a Imagem 5 mostra, ainda é possível verificar possíveis exemplos das práticas livreiras da J. Leite, que, na já citada obra Conversão miraculosa da felice aegypciaca penitente (imagem à esquerda) e no exemplar de Pão partido em pequeninos para os pequeninos da Casa de Deos, de 1696 (imagem à direita), fez o registro manuscrito a lápis em que provavelmente atesta a completude da obra.

A partir da análise das marcas de proveniência nos exemplares de Homero Pires, tanto daquelas deixadas por ele, quanto pelo uso que ele faz daquelas registradas por outras pessoas que tiveram acesso aos seus livros, é possível entender parte das relações simbólicas do bibliófilo com estes objetos.

Principalmente, pela identificação dos valores atribuídos por ele aos seus livros, sendo observável todas as variações definidas por Anciães $\left(2005^{16}\right.$, apud PEDRÃO; MURGUIA, 2013), como os valores artístico, de raridade, de autoria, de coleção e contexto e identidade, identificados nas anotações de Homero Pires 
sobre a presença de gravuras nos exemplares, ou sobre a escassez de exemplares de determinado título, ou a relevância dos autores, dos editores e de outros envolvidos na produção do livro. Da mesma forma, também se percebe a atribuição de valor, a partir dos registros sobre a presença ou ausência de suas obras em outras coleções de referência ou mesmo nas marcas de proveniência de outros colecionadores, que ajudam a traçar a sequência histórica de apropriação formal dos seus exemplares.

\section{Considerações finais}

Diante do apresentado, verificou-se que Homero Pires deixou em suas anotações não só uma possibilidade de entender o seu universo particular no colecionismo bibliográfico e a sua relação com os exemplares analisados, mas também a memória da prática do colecionismo bibliográfico naquele espaço-tempo em que viveu, além de entregar elementos que podem ajudar na construção da História do Livro, da circulação de exemplares e da atuação de livrarias brasileiras que vendiam livros raros, principalmente se associados às marcas de proveniência criadas por outras pessoas que também tiveram contato com os itens.

A análise das marcas de proveniências nas obras dos séculos XVI e XVII que pertenceram a Homero Pires revelaram o uso de três marcas de posse (ex libris, super-libros e assinatura) deste colecionador, que, apesar de colecionador de ex libris, preferia usar a assinatura como método principal de indicação de propriedade. Também foi possível verificar como esse bibliófilo fazia uso das bibliografias especializadas para identificação de informações sobre autores e obras. Mas, principalmente, foi possível ver como ele usava esses trabalhos para atribuição de raridade dos seus livros. Também auxiliava nesse processo os catálogos de leilões e a busca por exemplares em bibliotecas públicas e particulares de referência, essenciais para desvendar parte do arcabouço simbólico atribuído por Homero Pires a seus livros.

A atuação das livrarias brasileiras na venda de livros raros foi observada apenas em relação àquelas que atuavam na cidade do Rio de Janeiro, visto que a ampla maioria das proveniências destes espaços comerciais são de livrarias cariocas. Destaca-se a atuação da Livraria J. Leite, que forneceu uma quantidade 
considerável de obras à coleção de Homero Pires, sendo uma das referências na venda de obras raras no Brasil, fato reforçado pelo uso que ele fazia dos boletins desta livraria para estabelecimento da raridade e valor venal dos exemplares. Também era uma referência na análise das obras o catálogo da biblioteca de Solidônio Leite, que era pai do proprietário da J. Leite, considerado por alguns como o encarregado pelos negócios da livraria.

Além do que foi demonstrado, a presente pesquisa também reforça a importância dos estudos de marcas de proveniência para o entendimento da circulação e mercado de livros no Brasil, assim como das práticas individuais e coletivas de colecionismo bibliográfico. Apresentando elementos iniciais que, somados a outros estudos com perspectivas similares, podem reforçar e revelar características das redes de relacionamentos para venda e circulação de livros em território nacional.

\section{Financiamento}

Decanato de Pesquisa e Inovação da Universidade de Brasília.

\section{Agradecimentos}

Agradeço ao Professor André Gustavo de Melo Araújo e à bibliotecária Néria Lourenço, pela parceria na realização do projeto para levantamento de características materiais dos livros dos séculos XVI e XVII da BCE, que foi o embrião para a realização deste artigo. Assim como, aos alunos do curso de História da UnB que nos ajudaram nesta empreitada. Agradeço também à Professora Márcia Carvalho Rodrigues, da FURG, pelas indicações de textos sobre marcas de proveniência.

\section{Referências}

ARAÚJO, Diná Marques Pereira; REIS, Alcenir Soares dos; SILVEIRA, Fabrício José Nascimento da. Bibliofilia, bibliografias e a construção do sistema axiológico da raridade. Informação \& Informação, Londrina, v. 23, n. 2, p. 3857, maio/ago. 2018.

BERTINAZZO, Stella Maris de Figueiredo. Ex libris: pequeno objeto do desejo. Brasília: EdUnB, 2012. 
CARREÑO VELÁZQUEZ, Elvia. Marcas de propriedad em los libros novohispanos. 2. ed. Toluca de Lerdo: Fondo Editorial Estado de México, 2015.

CARVALHO, Cláudia de Jesus Carvalho; ALMEIDA, Carlos Cândico de Almeida. O caráter simbólico dos livros: possibilidades interpretativas para o colecionismo bibliográfico. In: COLÓQUIO EM ORGANIZAÇÃO, ACESSO E APROPRIAÇÃO DA INFORMAÇÃO E DO CONHECIMENTO, 4., 2019, Londrina. Anais [...]. Londrina: UEL, 2019. p. 264-278.

CATALOGO da livraria do fallecido conselheiro Thomaz Norton, a qual se ha de pôr á venda em leilão publico na rua de Cedofeita, n. ${ }^{\circ} 79$ nos dias 27 de julho, e seguintes. Porto: Typ. de Sebastião José Pereira, 1860.

CONSORTIUM OF EUROPEAN RESEARCH LIBRARIES. Provenance information. London, 2020.

FARIA, Maria Isabel; PERICÃO, Maria da Graça. Dicionário do livro: da escrita ao livro eletrônico. São Paulo: Edusp, 2008.

FUNDAÇÃO GETÚLIO VARGAS. Centro de Pesquisa e Documentação de História Contemporânea do Brasil. Homero Pires: verbete. Rio de Janeiro, 2009.

GALBRAITH, Steven K.; SMITH, Geoffrey D. Rare book librarianship: an introduction and guide. Santa Barbara: Libraries Unlimited, 2012.

GREENHALGH, Raphael Diego; MANINI, Miriam Paula. Análise bibliológica: ferramenta de segurança em coleções de livros raros. Encontros Bibli, Florianópolis, v. 20, n. 42, p. 17-29, jan./abr. 2015.

JOSSERAND, Claire. Les données de provenance des collections des bibliothéques. Lyon: Mémoire d'étude, 2016.

HALLEWELL, Laurence. O livro no Brasil. São Paulo: Edusp, 2012.

LACERDA, Ana Regina Luz. A importância das bibliotecas particulares incorporadas aos acervos públicos: as coleções da Biblioteca Central da Universidade de Brasília. Revista Brasileira de Biblioteconomia e Documentação, São Paulo, v. 13, p. 2673-2689, 2017.

LEUNG, Colette. The journey of books: rare books and manuscripts provenance metadata in a digital age. 2016. Dissertação (Master of Arts in Humanities Computing and Master of Library and Information Studies) -School of Library and Information Studies, University of Alberta, Edmonton, 2016. 
LIMA, Luís Filipe Silvério. Palavra de Deos empenhada e desempenhada. In: ARAÚJO, André de Melo; LOURENÇO, Néria; GREENHALGH, Raphael Diego (eds.). Obras Raras da Biblioteca Central da Universidade de Brasília: séculos XVI e XVII. Brasília: Editora Universidade de Brasília. No prelo.

LOPES, Ana Julia; GONÇALVES, Maison Roberto Mendonça; RODRIGUES, Marcia Carvalho. Marcas de proveniência bibliográfica: desenvolvimento de ferramentas para seu armazenamento e reconhecimento. In: 45 ANOS DO CURSO DE BIBLIOTECONOMIA; XXII SEMANA ACADÊMICA; I FÓRUM DE EGRESSOS, 2020. Anais [...]. Rio Grande, RS: FURG, 2021. No prelo.

MACHADO, Ubiratan. A etiqueta de livros no Brasil: subsídios para uma história das livrarias brasileiras. São Paulo: Edusp, 2003.

MACHADO, Ubiratan. História das livrarias cariocas. São Paulo: Edusp, 2012.

MACHADO, Ubiratan. Sua excelência, o ex-líbris. In: COSTA E SILVA, Alberto da; MACIEL, Anselmo (org.). Livro dos ex-líbris. Rio de Janeiro: Academia Brasileira de Letras, 2014. p. 09-75.

MCKITTERICK, David. The invention of rare books: private interest and public memory, 1600-1840. New York: Cambridge Universty Press, 2018.

MORAES, Rubens Borba de. O bibliófilo aprendiz. 4. ed. Brasília: Briquet De Lemos, 2005.

MURGUIA, Eduardo Ismael. O colecionismo bibliográfico: uma abordagem do livro para além da informação. Encontros Bibli, Florianópolis, n. esp., 1. sem., 2009.

PEDRÃO, Gabriela Bazan; MURGUIA, Eduardo Ismael. Formação das bibliotecas: uma abordagem desde a perspectiva do colecionismo. Em Questão, v. 19, n. 2, jul./dez. 2013.

PINHEIRO, Priscila da Costa; VICENTE, Sérgio Augusto. Uma marca de propriedade: os ex libris no Museu Mariano Procópio (Juiz de Fora - MG). Jornal Aldrava Cultural, Mariana, 14 de fev. 2019.

POMIAN, Krzysztof. Coleção. In: GIL, Fernando. (org.). Enciclopédia Einaudi. v. 1. Porto: Imprensa Nacional: Casa da Moeda, 1984. p. 51-86.

RIBEIRO, Renato Janine. Memórias de si, ou... Estudos Históricos, Rio de Janeiro, v. 11, n. 21, p. 35-42, 1998. 
RODRIGUES, Marcia Carvalho; VIAN, Alissa Esperon; TEIXEIRA, Heytor Diniz. Marcas de procedência: contribuições para o estudo do livro raro. Encontros Bibli, Florianópolis, v. 25, p. 1-20, 2020.

SANTOS, José dos. Catálogo da importante e preciosíssima livraria que pertenceu aos notáveis escritores e bibliófilos Condes de Azevedo e de Samodães. Porto: Tip. da Empresa Literária e Tipográfica, 1921.

SUNDSTRÖM, Admeire da Silva Santos; ALBUQUERQUE, Ana Cristina. Colecionismo bibliográfico: contexto histórico, terminologia e perspectivas de estudo na Ciência da Informação. Em Questão, Porto Alegre, v. 26, n. 3, p. 250-275, set/dez. 2020.

SUNDSTRÖM, Admeire da Silva Santos.; BIZELLO, Maria Leandra. Coleção de livros e a memória nas entrelinhas: análise da coleção Amidicis Tocantins. In: ENCONTRO NACIONAL DE PESQUISA EM CIÊNCIA DA INFORMAÇÃO, 17., 2016, Salvador. Anais [...]. Salvador UFBA, 2016, p. 116.

TARTAGLIA, Ana Roberta de Souza. As encadernações da coleção de obras raras e especiais da Casa de Oswaldo Cruz: um estudo para sua preservação. 2018. Dissertação (Mestrado Profissional em Preservação e Gestão do Patrimônio) - Fundação Oswaldo Cruz, Rio de Janeiro, 2018. ZÚQUETE, Afonso Eduardo Martins (coord.). Nobreza de Portugal e do Brasil. Lisboa: Editorial Enciclopédia, 1960-1961. v. 3.

\section{APÊNDICE A - OBRAS DA BCE}

AIRES, Francisco. Teatro dos triunfos divinos contra os disprimores humanos. Lisboa: Paulo Craesbeeck, 1658.

ALMEIDA, Manuel de. História geral de Ethiopia a alta. Coimbra: Manoel Dias, 1660.

BERNARDES, Manuel. Luz, e calor: obra espiritual. Lisboa: Miguel Deslandes, 1696.

BERNARDES, Manuel. Pão partido em pequeninos para os pequeninos da Casa de Deos. Lisboa: Antônio Pedroso Galrão, 1696.

CAMÕES, Luís Vaz de. Lusíadas. Lisboa: A. C. Dimello, 1670.

CAMÕES, Luís Vaz de. Rimas várias. Lisboa: Craesbeeckiana, 1689. Tomo III. Encadernado com os tomos I e II. 
CAMÕES, Luís Vaz de. Rimas várias. Lisboa: Theotonio Damaso de Mello, 1685. Tomos I e II. Encadernados com o tomo III.

COSTA, Leonel da. Conversão meraculosa da felice AEgypcia penitente $\mathbf{S}$. Maria: sua vida, e sua morte. Lisboa, Pedro Vansi-becarspel, 1674.

FARIA, Tomé de. Lvsiadvm: libri decem. Lisboa: Ulyssipone, 1622.

MELLO, Francisco Manuel de. Ecco político. Lisboa: Paulo Craesbeck, 1645.

MONTEIRO, Diogo. Meditações dos atributos divinos. Roma: Angelo Bernábo, 1671.

PARADA, Antônio Carvalho de. A arte de reynar. Bucelas: Paulo Crasbeck, 1644.

PEREIRA DE CASTRO, Gabriel. Ulyssea ou Lisboa edificada: poema heroico. Lisboa: Lourenço Crasbeeck, 1636.

PINA, Rui de. Chronica de el Rey Dom Afonso o quarto do nome, e settimo dos reys de Portugal. Lisboa: Paulo Craesbeeck, 1653.

ROBOREDO, Amaro de. Porta de linguas. Lisboa: Ulyssipione, 1623.

Encadernado com Raizes da língua latina.

ROBOREDO, Amaro de. Raizes da língua latina. Lisboa: Ulyssipione, 1621. Encadernado com Porta de línguas.

VIEIRA, Antônio. Palavra de Deos empenhada e desempenhada. Lisboa: Miguel Deslandes, 1690.

\section{APÊNDICE B - BIBLIOGRAFIAS ESPECIALIZADAS}

BOLETIM bibliografico [da] Livraria J. Leite. Rio de Janeiro: A Livraria, [192?]

CATALOGO annotado da Bibliotheca de Solidonio Leite: primeira parte: Classicos do catalogo da Academia. Rio de Janeiro: J. Leite, [1920].

PINTO DE MATTOS, Ricardo. Manual bibliographico portuguez de livros raros, classicos e curiosos. Porto: Livraria Portuense, 1878.

SANTOS, José dos. Catálogo da importante e preciosíssima livraria que pertenceu aos notáveis escritores e bibliófilos Condes de Azevedo e de Samodães. Porto: Tip. da Empresa Literária e Tipográfica, 1921. 
SILVA, Innocencio Francisco da. Diccionário bibliográphico portuguez: estudos aplicaveis a Portugal e ao Brasil. Lisboa: Impr. Nacional, 1858-1958. 23 v.

\section{Homero Pires: bibliographic collecting and provenance records}

Abstract: The present work consists of the survey, description and documentary analysis of the provenance records left by the politician and bibliophile Homero Pires in his books from the 16th and 17th centuries. Of the 165 books from this period present in the Rare Books Section of the Central Library (BCE) of the University of Brasília (UnB), 92 belonged to the aforementioned collector. In addition to the notes and possession records left by the bibliophile, the provenance records of those who previously had contact with the specimens were also observed. Therefore, it was found, among other things, that these records present relevant information on the circulation of books, on the practices of bibliographic collecting and on the market for rare works in Brazil in the first half of the 20th century.

Keywords: Homero Pires; Bibliophilia; Rare books; Provenance records; Material Bibliography.

Recebido: $17 / 02 / 2021$

Aceito: 02/06/2021

\section{Declaração de autoria:}

Concepção e elaboração do estudo: Raphael Diego Greenhalgh.

Coleta de dados: Raphael Diego Greenhalgh.

Análise e interpretação de dados: Raphael Diego Greenhalgh.

Redação: Raphael Diego Greenhalgh.

Revisão crítica do manuscrito: Raphael Diego Greenhalgh

\section{Como citar:}

GREENHALGH, Raphael Diego. Homero Pires: o colecionismo bibliográfico e as marcas de proveniência. Em Questão, Porto Alegre, v. 28, n. 1, p. 402-431, 2022. DOI: http://dx.doi.org/10.19132/1808-5245281.402-431

\footnotetext{
${ }^{1}$ Machado (2014, p. 11) diz que "ex libris é uma expressão latina, formada pelo ablativo plural de liber (libris) e a preposição indicativa de proveniência. O autor ainda se refere ao uso restrito do termo ex libris, que é como foi usado neste trabalho, sendo "uma pequena gravura, emitida em série, que se cola na contraapa ou na guarda do livro, como símbolo de propriedade, na qual figuram a expressão ex libris, uma ilustração (brasão, monograma, alegoria etc.), o nome do titular e uma divisa, nenhum desses itens sendo obrigatório".
} 
${ }^{2}$ Super-libros: "[loc. lat.] designa uma marca de ex-libris gravada nas pastas superior e/ou inferior de uma encadernação, geralmente guarnecida com as armas, nome, divisa, emblema ou outros elementos relacionados com o possuidor da obra". (FARIA; PERICÃO, 2008, p. 683)

3 Tartaglia (2018) dividiu os elementos que levantou em sua tese sobre encadernações, em: marcas de propriedade e marcas de circulação.

${ }^{4}$ LOCK, Margaret. Two centuries of bookbinding: materials and techniques 1700-1900. Exhibition catalogue. Toronto, Canadá: The Canadian bookbinders and book artist guild, 1991. Apud Tartaglia (2018).

${ }^{5}$ No original: “[...] as a chronology of owners, custody, or location of an historical book. It includes not only names, but other contextual information of interest to book history (such as time and place) to allow further understandings of people's interactions with books over time" (LEUNG, 2016, p. 11).

${ }^{6}$ No original: "[...] comme toute trace sur un livre ou em dehors de celui-ci fournissant la preuve contextuelle et circonstancielle de as production d'origine ou de sa découverte, et permettant de retracer, autant que possible, son histoire, en particulier les séquences de son appropriation formelle." (JOSSERAND, 2016, p. 12).

7 No original: "Books could be gathered and used far from their places of origin". (MCKITTERICK, 2018, p. 42).

8 No original: "The geography of production was very diferente from the geography of use." (MCKITTERICK, 2018, p. 43).

${ }^{9}$ No original: "En este sentido, lector, bibliotecario y amantes de los libros crean distintivos con letras, imágenes o signos que los identifican y a través de los cuales los autodefine y les da un valor." (CARREÑO VELÁZQUEZ, 2015, p. 41).

${ }^{10}$ No original: "Interest in provenance information goes in and out of fashion. Once it was a bibliophilic interest concerned with authors' association copies and books belonging to great men. Following the rise of the history of the book in the 1980s and 1990s, provenance studies have become an important ingredient in the work of social and cultural historians dealing with questions of readership and literacy. The ownership of books by craftsmen and women is now as significant as that of kings and archbishops. At the same time, a separate development of concern about the security of library collections has widened interest in recording provenances of all sorts, ancient and modern." (CONSORTIUM OF EUROPEAN RESEARCH LIBRARIES, 2020, s.p.).

${ }^{11}$ Foram usadas as barras duplas // para a indicação de quebra de linha no documento original. Também foi mantida a grafia original nestas citações.

${ }^{12}$ Essa aquisição provavelmente aconteceu em 1860, no leilão da livraria de Thomaz Norton, realizada em razão de seu falecimento. A obra consta como o item 167, da estante $\mathrm{F}$, do catálogo do referido leilão (CATALOGO..., 1860, p. 40)

${ }^{13}$ Disponível em: http://naude.bibliothequemazarine.fr/F?func=direct\&local_base=bif01\&l_base=bif01\&doc_number=000262051\&format=999. Acesso em: 05 jan. 2021.

${ }^{14}$ A biblioteca do Conde de Azevedo foi deixada para o seu primo, o $2^{\circ}$ Conde de Samodães. (ZÚQUETE, 1960)

${ }^{15}$ Esta data é apresentada por Machado (2012, p. 182). Contudo, Hallewell (2012, p. 462) diz que o encerramento das atividades da Livraria J. Leite foi em 1973.

${ }^{16}$ ANCIÃES, Alfredo Ramos. Quando objectos de colecção falam das (tele)comunicações. Episteme, Porto Alegre, n. 21, jan./jun. 2005. Suplemento especial. Apud Pedrão e Murguia (2013). 